\title{
Analysis of the clinical characteristics of insulin autoimmune syndrome induced by exogenous insulin in diabetic patients
}

\author{
Zuojun Li', Dan Yi ${ }^{2}$, Lijuan Zheng ${ }^{3}$, Shiran $\mathrm{Li}^{3}$, Weijin Fang ${ }^{1}$ and Chunjiang Wang ${ }^{1^{*}(\mathbb{D})}$
}

\begin{abstract}
Background: The exact incidence, clinical features and uniform diagnostic criteria of exogenous insulin autoimmune syndrome (EIAS) are still unclear. The purpose of this study is to explore the clinical characteristics of EIAS and to provide a structural approach for clinical diagnosis, treatment and prevention.

Methods: The literature on EIAS in Chinese and English from 1970 to 2020 was collected for retrospective analysis.

Results: A total of 122 patients ( 33 males and 73 females) were included in the study with a median age of 67 years (range 14-86) and a median HbA1c of 7.7\%. ElAS mainly occurred in type 2 diabetes mellitus patients using premixed insulin. Symptoms manifested were hypoglycemia in $86.54 \%$, recurrent episodes of symptomatic hypoglycemia in $35.58 \%$, nocturnal hypoglycemia along with daytime hyperglycemia in $21.15 \%$ and recurrent hypoglycemia after discontinued insulin in $64.43 \%$. The onset of symptoms occurred at night, in the early morning or during fasting, ranging from a few days to 78 months after the administration of insulin. The mean blood glucose level during the hypoglycemic phase was $2.21 \mathrm{mmol} / \mathrm{L}$ (range 1-3.4), and the serum insulin levels were mainly $\geq 100 \mathrm{U} / \mathrm{mL}$ and were associated with low C-peptide levels ( $\leq 10 \mathrm{ng} / \mathrm{ml}$ ). Insulin autoantibodies (IAAs) were positive in all EIAS patients. The $75-\mathrm{g}$ extended oral glucose tolerance test (OGTT) mainly showed a diabetic curve. Pancreatic imaging was unremarkable. Withdrawal of insulin alone or combination of oral hypoglycemic agents or replacement of insulin formulations or with corticosteroid treatment eliminated hypoglycemia in a few days to 3 months. IAA turned negative in 6 months (median, range 1-12). No hypoglycemia episodes were observed at a median follow-up of 6 months (range 0.5-60).

Conclusions: EIAS is an autoimmune disease caused by insulin-binding antibodies in susceptible subjects. Insulin antibodies change glucose dynamics and could increase the incidence of hypoglycemic episodes. Detection of insulin antibodies is the diagnostic test. Changing therapeutic modalities reduced the incidence of hypoglycemic episodes.
\end{abstract}

Keywords: Insulin autoimmune syndrome, Exogenous insulin, Insulin autoantibodies, Hypoglycemia

\footnotetext{
*Correspondence: wongcj@csu.edu.cn

1 Department of Pharmacy, The Third Xiangya Hospital, Central South University, No. 138 Tongzipo Road, YueLu District, Changsha 410013, Hunan, China

Full list of author information is available at the end of the article
}

\begin{abstract}
Background
Insulin autoimmune syndrome (IAS) is a rare cause of hypoglycemia and is also known as Hirata's disease, which was first described in 1970 [1]. Classic IAS is characterized by extremely high serum insulin concentrations, elevated insulin autoantibody (IAA) titers, no prior exposure to exogenous insulin, and no pathological abnormalities of the pancreatic islets and has numerous presentations, such as being triggered in some by food
\end{abstract}

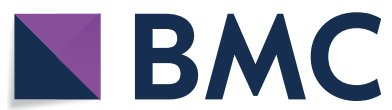

(c) The Author(s) 2021. This article is licensed under a Creative Commons Attribution 4.0 International License, which permits use, sharing, adaptation, distribution and reproduction in any medium or format, as long as you give appropriate credit to the original author(s) and the source, provide a link to the Creative Commons licence, and indicate if changes were made. The images or other third party material in this article are included in the article's Creative Commons licence, unless indicated otherwise in a credit line to the material. If material is not included in the article's Creative Commons licence and your intended use is not permitted by statutory regulation or exceeds the permitted use, you will need to obtain permission directly from the copyright holder. To view a copy of this licence, visit http://creativeco mmons.org/licenses/by/4.0/. The Creative Commons Public Domain Dedication waiver (http://creativecommons.org/publicdomain/ zero/1.0/) applies to the data made available in this article, unless otherwise stated in a credit line to the data. 
intake and fasting in others [2]. IAS can be spontaneous or triggered by exposure to viruses or drugs [3]. Among them, drugs containing sulfhydryl groups are among the important triggers, such as methimazole, lipoic acid, glutathione, and penicillamine [4].

In recent years, hypoglycemia induced by exogenous insulin in diabetic patients has also shown symptoms similar to IAS. Some scholars named it exogenous insulin autoimmune syndrome (EIAS) as a nonclassic IAS [5]. EIAS exists in the published literature in the form of case reports that are gradually increasing in number. However, the exact incidence, clinical features and uniform diagnostic criteria of EIAS are still unclear. The evidence of IAS induced by exogenous insulin treatment is limited to case reports. In this study, we collected patients with exogenous insulin-induced autoimmune hypoglycemia to summarize the clinical features, diagnostic tests, treatment and prevention.

\section{Methods}

We searched the Wanfang Data, China National Knowledge Infrastructure (CNKI), and Chinese VIP databases, PubMed/Medline, Web of Knowledge, OVID, Elsevier, Springer Link, Embase and Cochrane Library in Chinese and English from 1970 to 2020 and collected case reports and case analyses of exogenous insulin-induced insulin antibody syndrome for inclusion as preliminary studies. We identified the literature regarding insulin antibody syndrome induced by exogenous insulin using the search terms "insulin antibody syndrome", "exogenous insulin", "autoimmune hypoglycemia", "hypoglycemia" and "Hirata disease".

Inclusion and exclusion criteria: We collected case reports and case analyses of exogenous insulin-induced IAS for inclusion as preliminary studies. All EIAS patients were diagnosed based on hypoglycemia and laboratory tests, such as serum insulin level, C-peptide concentration and IAA. Duplicate cases, mechanistic studies, animal studies, review articles, sulfhydryl drugs or other factors that induce IAS, articles with incomplete data and articles that were only abstracts or lacked a full text were excluded.

\section{Results}

\section{Patients' criteria}

We screened a total of 2372 studies. After careful review by the two independent authors, only 56 studies, including 122 patients ( 87 males and 35 females), were included in the study. The median age of the patients was 67 years (range 14-86), the median duration of diabetes was 10 years (range $0.25-42$ ), and the median HbA1c was 7.7\% (range 5.4-14.4) (Table 1). Among the patients reported in the literature, 119 patients (97.54\%) were from Asia, 100 patients (90.91\%) had type 2 diabetes mellitus (T2DM), and 6 patients (5.45\%) had type 1 diabetes mellitus (T1DM). One patient (0.82\%) simultaneously took clopidogrel, which may cause IAS. Eight patients (6.56\%) had autoimmune diseases.

\section{Administration of insulin}

The administration of insulin is shown in Table 1. The median daily dose of insulin was 26 IU (range 8-95). The median time of insulin was 12 months (range 0.07-78) before the onset of hypoglycemia. EIAS occurred in 72 patients $(62.61 \%)$ using premixed insulin, 29 patients (25.22\%) using insulin analogs, 19 patients (16.52\%) using recombinant human insulin, and 4 patients $(3.48 \%)$ using animal-derived insulin. Among 72 patients using premixed insulin, 36 patients $(50.00 \%)$ and 35 patients (48.61\%) used premixed human insulin and premixed insulin analogs, respectively. In patients with EIAS caused by insulin analogs, insulin aspart in 18 patients $(62.07 \%)$ and glargine in 10 patients $(34.48 \%)$ were the most common insulin analogs, followed by insulin detemir and insulin lispro in 5 patients (17.24\%). Fourteen patients $(73.68 \%)$ given short-acting human insulin and 11 patients $(57.89 \%)$ given intermediate-acting human insulin were associated with EIAS induced by recombinant human insulin. Premixed insulin-related IAS most often occurred in 15 patients (41.67\%) using Novolin 30R, 14 patients (38.89\%) using Humulin 70/30 and 32 patients (91.42\%) using Aspart 30.

\section{Clinical presentation}

The clinical manifestations of EIAS in 104 patients $(85.25 \%)$ are described in Table 2. EIAS mainly manifested as hypoglycemia in 90 patients $(86.54 \%)$ and also manifested as hyperglycemia in 27 patients $(30.00 \%)$ or without any symptoms of hypoglycemia in 4 patients (3.85\%). Eleven patients (10.58\%) with EIAS were also hospitalized with hyperglycemia, and even 4 patients were hospitalized with ketoacidosis (36.36\%). Fourteen patients $(13.46 \%)$ with EIAS also had allergic reactions that were simultaneous with the occurrence of hypoglycemia, which manifested as rash, pruritus, redness and swelling. Hypoglycemia mainly manifested as symptoms of the autonomic nervous system in 48 patients (53.33\%), including palpitations, sweating, hunger and hand tremors, followed by neurological hypoglycemia in 27 patients (30.00\%), including dizziness, coma, blurred consciousness, anxiety, fear, abnormal behavior and incontinence. In addition, recurrent episodes of symptomatic hypoglycemia occurred in 37 patients (35.58\%), and nocturnal hypoglycemia along with daytime hyperglycemia occurred in 22 patients (21.15\%). Sixty-seven patients (64.43\%) still had recurrent hypoglycemia after insulin 
Table 1 General data of 122 patients reported in case series/reports

\begin{tabular}{|c|c|c|}
\hline \multicolumn{2}{|l|}{ Parameter } & \multirow{2}{*}{$\begin{array}{l}\text { Value } \\
67(14,86)^{b}\end{array}$} \\
\hline Age $(122)^{a}$ & Years & \\
\hline \multirow[t]{2}{*}{ Sex } & Male & $87 / 122(71.31 \%)$ \\
\hline & Female & $35 / 122(28.69 \%)$ \\
\hline $\mathrm{BMI}(76)^{\mathrm{a}}$ & $\mathrm{kg} / \mathrm{m}^{2}$ & $23(18.4,33.8)^{\mathrm{b}}$ \\
\hline $\operatorname{HbA1c}(101)^{\mathrm{a}}$ & $\%$ & $7.7(5.4,14.4)^{b}$ \\
\hline \multirow[t]{6}{*}{ Region } & China & $105 / 122(86.07 \%)$ \\
\hline & Japan & $12 / 122(9.64 \%)$ \\
\hline & India & $1 / 122(0.82 \%)$ \\
\hline & Finland & $1 / 122(0.82 \%)$ \\
\hline & Korea & $1 / 122(0.82 \%)$ \\
\hline & USA & $2 / 122(1.64 \%)$ \\
\hline \multirow[t]{4}{*}{ Indication for insulin (110) ${ }^{\mathrm{a}}$} & T1DM & $6 / 110(5.45 \%)$ \\
\hline & T2DM & $100 / 110(90.91 \%)$ \\
\hline & LADA & $3 / 110(2.73 \%)$ \\
\hline & Pancreatic exocrine disease* & $1 / 110(0.91 \%)$ \\
\hline Course of diabetes $(118)^{\mathrm{a}}$ & Years & $10(0.25,42)^{b}$ \\
\hline Concomitant sulfhydryl drugs & Clopidogrel & $1 / 122(0.82 \%)$ \\
\hline Concomitant autoimmune diseases & $\begin{array}{l}\text { Grave's diseases, Hashimoto's thyroiditis, sjogren syndrome, dermatitis eczematosa, } \\
\text { psoriasis, poliomyelitis, rheumatoid arthritis }\end{array}$ & $8 / 122(6.56 \%)$ \\
\hline Insulin dosage (100) ${ }^{\mathrm{a}}$ & IU/day & $26(8,95)^{b}$ \\
\hline Duration of insulin use (86) ${ }^{\mathrm{a}}$ & Months & $24(0.13,288)^{b}$ \\
\hline Insulin administration time before hypoglycemia $(48)^{\mathrm{a}}$ & Months & $12(0.07,78)^{b}$ \\
\hline \multirow[t]{24}{*}{ Insulin types $(115)^{\mathrm{a}}$} & Bovine and porcine insulin (4) ${ }^{a}$ & $4 / 115(3.48 \%)$ \\
\hline & Neutral protamine Hagedorn & $4 / 4(100 \%)$ \\
\hline & Insulin analogue (29) & $29 / 115(25.22 \%)$ \\
\hline & Aspart & $18 / 29(62.07 \%)$ \\
\hline & Glargine & $10 / 29(34.48 \%)$ \\
\hline & Lispro & $5 / 29(17.24 \%)$ \\
\hline & Detemir & $5 / 29(17.24 \%)$ \\
\hline & Glulisine & $1 / 29(3.45 \%)$ \\
\hline & No data & $1 / 29(3.45 \%)$ \\
\hline & Recombinant human insulin (19) ${ }^{\mathrm{a}}$ & $19 / 115(16.52 \%)$ \\
\hline & Short-acting insulin & $14 / 19(73.68 \%)$ \\
\hline & Intermediate-acting insulin & $11 / 19(57.89 \%)$ \\
\hline & Premixed insulin (72) & $72 / 115(62.61 \%)$ \\
\hline & Premixed human insulin & $36 / 72(50.00 \%)$ \\
\hline & Novolin 30R & $15 / 36(41.67 \%)$ \\
\hline & Humulin70/30 & $14 / 36(38.89 \%)$ \\
\hline & Novolin 50R & $4 / 36(11.11 \%)$ \\
\hline & Gansulin30R & $2 / 36(5.56 \%)$ \\
\hline & Gansulin50R & $1 / 36(2.78 \%)$ \\
\hline & Premixed insulin analogues & $35 / 72(48.61 \%)$ \\
\hline & Aspart 30 & $32 / 35(91.42 \%)$ \\
\hline & Lispro 25 & $3 / 35(8.57 \%)$ \\
\hline & Premixed animal-derived insulin & $1 / 72(1.39 \%)$ \\
\hline & Wan Sulin 30R** & $1 / 1(100 \%)$ \\
\hline
\end{tabular}

BMI, Body Mass Index; LADA, Latent Autoimmune Diabetes;T1DM, type 1 diabetes mellitus; T2DM, type 2 diabetes mellitus

${ }^{a}$ Represents the number of patients out of 122 on which information regarding this particular parameter was provided

${ }^{\mathrm{b}}$ Median (minimum-maximum)

* Total pancreatectomy for pancreatic adenocarcinoma

** Wan Sulin 30R contained 30\% porcine insulin and 70\% protamine zinc porcine insulin, which was produced by Wanbang Biopharmaceuticals in China 
Table 2 Clinical information on the122 included patients

\begin{tabular}{|c|c|c|}
\hline Parameter & & Value \\
\hline \multirow{10}{*}{ Clinical manifestations (104) } & Hypoglycemia & $90 / 104(86.54 \%)$ \\
\hline & Autonomic nervous system: palpitations, sweating, hunger and hand tremors & $48 / 90(53.33 \%)$ \\
\hline & $\begin{array}{l}\text { Neurological hypoglycemia: dizziness, coma, blurred consciousness, anxiety, fear, } \\
\text { abnormal behavior and incontinence }\end{array}$ & $27 / 90(30.00 \%)$ \\
\hline & Hypoglycemia & $11 / 104(10.58 \%)$ \\
\hline & Ketoacidosis & $4 / 11(36.36 \%)$ \\
\hline & No symptoms of hypoglycemia & $4 / 104(3.85 \%)$ \\
\hline & Allergic reaction: rash, pruritus, redness and swelling & 14/104 (13.46\%) \\
\hline & Recurrent episodes of symptomatic hypoglycemia & $37 / 104(35.58 \%)$ \\
\hline & Nocturnal hypoglycemia along with daytime hyperglycemia & $22 / 104(21.15 \%)$ \\
\hline & Recurrent hypoglycemia after discontinued insulin & $67 / 104(64.43 \%)$ \\
\hline \multirow[t]{3}{*}{ Onset time of hypoglycemia $(86)^{a}$} & Before meal & 16/86 (18.60\%) \\
\hline & Night and early morning and fasting & $68 / 86(70.07 \%)$ \\
\hline & 3 to $5 \mathrm{~h}$ after meal & $9 / 86(10.47 \%)$ \\
\hline \multirow[t]{6}{*}{ Blood glucose (mmol/L) } & Mean blood glucose during hypoglycemia $(70)^{a}$ & $2.21(1,3.4) b$ \\
\hline & $\leq 1$ & $1 / 70(1.43 \%)$ \\
\hline & $1-2$ & $32 / 70(45.71 \%)$ \\
\hline & $2-3$ & $34 / 70(47.57 \%)$ \\
\hline & $3-4$ & $3 / 70(4.29 \%)$ \\
\hline & Fasting blood glucose $(80)^{\mathrm{a}}$ & $5.59(1.24,13.9)^{b}$ \\
\hline \multirow[t]{10}{*}{ Insulin (5-25 mU/L) } & Insulin levels during hypoglycemia (44) ${ }^{\mathrm{a}}$ & \\
\hline & $50-100$ & $2 / 44(4.55 \%)$ \\
\hline & $100-300$ & $12 / 44(27.27 \%)$ \\
\hline & $300-1000$ & $12 / 44(27.27 \%)$ \\
\hline & $\geq 1000$ & 18/44 (40.91\%) \\
\hline & Fasting insulin levels (86) ${ }^{\mathrm{a}}$ & \\
\hline & $50-100$ & $11 / 86(12.79 \%)$ \\
\hline & $100-300$ & 20/86 (23.26\%) \\
\hline & $300-1000$ & $40 / 86(46.51 \%)$ \\
\hline & $\geq 1000$ & 15/86 (17.44\%) \\
\hline \multirow[t]{8}{*}{ C-peptide (1.1-4.4 ng/ml) } & C-peptide levels during hypoglycemia (39) & \\
\hline & $<5$ & $21 / 39(53.85 \%)$ \\
\hline & $5-10$ & $13 / 39(33.33 \%)$ \\
\hline & $10-50$ & $5 / 39(12.82 \%)$ \\
\hline & Fasting C-peptide levels (87) ${ }^{\mathrm{a}}$ & \\
\hline & $<5$ & $57 / 87(65.52 \%)$ \\
\hline & $5-10$ & 18/87 (20.69\%) \\
\hline & $\geq 10$ & 12/87 (13.79\%) \\
\hline \multicolumn{3}{|l|}{ Antibody } \\
\hline IAA $(122)^{\mathrm{a}}$ & Positive & $122 / 122(100 \%)$ \\
\hline ICA $(85)^{\mathrm{a}}$ & Positive & $8 / 85$ (9.41\%) \\
\hline GADA (89) ${ }^{\mathrm{a}}$ & Positive & 7/89 (7.87\%) \\
\hline \multirow[t]{3}{*}{$\mathrm{OGTT}(65)^{\mathrm{a}}$} & IGT & 6/65 (9.23\%) \\
\hline & Diabetic curve & 59/65 (90.77\%) \\
\hline & 3-to 5-h hypoglycemia & 14/39 (35.60\%) \\
\hline
\end{tabular}

CT, computed tomography; GADA, Glutamic Acid Decarboxylase Antibody; ICA, Islet Cell Autoantibody; IGT, impaired glucose tolerance; OGTT, oral glucose tolerance test

a Represents the number of patients out of 106 on which information regarding this particular parameter was provided

b Mean (minimum-maximum) 
was discontinued. The time of onset of hypoglycemia was largely at night and in the early morning and during fasting in 68 patients (65.06\%), before meals in 16 patients $(18.60 \%)$ and 3 to $5 \mathrm{~h}$ after meals in 9 patients $(10.47 \%)$.

\section{Laboratory tests}

The laboratory test results related to EIAS are summarized in Table 2. The mean blood glucose level at the onset of hypoglycemia was $2.21 \mathrm{mmol} / \mathrm{L}$ (range 1-3.4), and 66 patients $(94.29 \%)$ had blood glucose levels of $\leq 3 \mathrm{mmol} / \mathrm{L}$ during hypoglycemic episodes. The serum insulin levels were $\geq 1000 \mathrm{U} / \mathrm{mL}$ in 18 patients $(40.91 \%)$ during the onset of hypoglycemia and 100-1000 U/ml in 42 patients $(95.45 \%)$. C-peptide was $<10 \mathrm{ng} / \mathrm{ml}$ in 34 patients $(87.18 \%)$. The mean fasting blood glucose level was $5.59 \mathrm{mmol} / \mathrm{L}(1.24,13.9)$ in 80 patients, accompanied by fasting insulin levels $\geq 100 \mathrm{U} / \mathrm{mL}$ in 75 patients (87.21\%), and fasting C-peptide levels were $\leq 10 \mathrm{ng} / \mathrm{ml}$ in 75 patients $(86.21 \%)$. All 122 EIAS patients were positive for IAA, 8 patients $(9.41 \%)$ were ICA positive, and 9 patients $(7.87 \%)$ were glutamic acid decarboxylase antibody (GADA) positive. Seven patients (5.74\%) employed a continuous glucose monitor (CGM).

The 75-g extended oral glucose tolerance test (OGTT) showed diabetic curves in 59 patients (90.77\%), impaired glucose tolerance (IGT) in 6 patients (9.23\%), and 3- to 5-h hypoglycemia in 14 patients $(35.60 \%)$. Nine patients underwent histocompatibility leukocyte antigen (HLA) genotype testing, of whom 7 patients were related to HLA-DR4 and 4 patients were related to HLA-DQ3. HLA-DR4 showed DRB1*0405/1302, DRB1*0405/080302, DRB1*0406, DRB1*080302/090102 and HLA-DRB1*0406/040101. HLA-DQ3 showed DQB1*0401/*0604, DQA1*0302DQB1*0302/0303, DQA1*0601/0102-DQB1*0604 and DQB1*030201/050101.

\section{Imaging examination}

The imaging examination of EIAS patients mainly included pancreas computed tomography (CT) in 50 patients, magnetic resonance imaging (MRI) in 9 patients and abdominal ultrasound in 14 patients (Table 3). CT scans showed normal pancreas in 48 EIAS patients (96\%) and focal cystic change and slightly full pancreatic head in 1 patient (2\%). Both MRI and ultrasound showed a normal pancreas in EIAS patients.

\section{Treatment and prognosis}

A total of 122 patients (100\%) eventually stopped receiving EIAS-related exogenous insulin and were given small, frequent meals and low-carbohydrate treatment (Table 3). A total of 68 patients $(55.74 \%)$ switched to oral hypoglycemic drugs, 33 patients $(27.05 \%)$ switched to other insulin types, 20 patients $(16.39 \%)$ adopted lifestyles without hypoglycemic drugs, 39 patients (31.97\%) were given glucocorticoid therapy, and 4 patients

Table 3 Imaging examination, treatment and prognosis of 122 EIAS patients reported in case series/reports

\begin{tabular}{|c|c|c|}
\hline Parameter & & Value \\
\hline \multicolumn{3}{|l|}{ Imaging examination } \\
\hline \multirow[t]{3}{*}{$C T(50)^{\mathrm{a}}$} & Normal & 48/50 (96\%) \\
\hline & Focal cystic change & $1 / 50(2 \%)$ \\
\hline & Slightly full pancreatic head & $1 / 50(2 \%)$ \\
\hline $\operatorname{MRI}(9)^{\mathrm{a}}$ & Normal & 9/9 (100\%) \\
\hline Ultrasound (14) ${ }^{\mathrm{a}}$ & Normal & $14 / 14(100 \%)$ \\
\hline \multirow[t]{7}{*}{ Therapy $(122)^{\mathrm{a}}$} & Discontinued insulin & $122 / 122(100 \%)$ \\
\hline & Switch to oral hypoglycemic drugs & $68 / 122(55.74 \%)$ \\
\hline & Switch to another insulin type & $33 / 122(27.05 \%)$ \\
\hline & Lifestyle modification & 20/122 (16.39\%) \\
\hline & Medical Nutrition therapy & $1 / 122(0.82 \%)$ \\
\hline & Corticosteroids & $39 / 122(31.97 \%)$ \\
\hline & Plasmapheresis & $4 / 122(3.28 \%)$ \\
\hline \multirow[t]{2}{*}{ Hypoglycemia disappearance time $(45)^{\mathrm{a}}$} & Corticosteroids (Months) & $1(0.07,6)^{b}$ \\
\hline & Non-corticosteroids (Months) & $2(0.03,8)^{b}$ \\
\hline IAA turn negative time $(20)^{\mathrm{a}}$ & Months & $6(1,12)^{b}$ \\
\hline Follow-up time $(55)^{\mathrm{a}}$ & Months & $6(0.5,60)^{b}$ \\
\hline
\end{tabular}

$\mathrm{CT}$, computed tomography; MRI, magnetic resonance imaging;

a Median (minimum-maximum)

b Represents the number of patients out of 122 on which information regarding this particular parameter was provided 
(3.28\%) were treated with plasmapheresis. Interestingly, 1 patient was given medical nutrition therapy for EISA and achieved good clinical effects [6]. The median times to disappearance of hypoglycemia were 1 month (range 0.07-6) in the corticosteroid treatment group and 2 months (range 0.03-8) in the noncorticosteroid treatment group. The median time for IAA to become negative was 6 months (range 1-12). None of the patients had EIAS-related hypoglycemia episodes at a median followup of 6 months (range $0.5-60$ ).

\section{Discussion}

Hypoglycemia is the most common acute complication of diabetic patients receiving antidiabetic therapies, especially those receiving insulin therapies, and can be easily improved by adjusting the insulin dose or improving one's lifestyle. In recent years, the incidence of autoimmune hypoglycemia has gradually increased due to increased administration of exogenous insulin. The primary diagnostic criteria are the presence of insulinbinding antibodies, high insulin and low C-peptide [7], although these criteria are not universally accepted [2].

Our research showed that EIAS may occur in diabetic patients using various types of insulin, especially T2DM patients who use premixed insulin human insulin and premix analogs. HbA1c, which represents 2-month glycemia, was usually $>7 \%$ in EIAS patients [8]. The condition occurred 2 days to 78 months after insulin administration. Patients with EIAS mainly showed symptoms of the autonomic nervous system, such as palpitations, sweating, and hunger. Some patients may have skin allergic reactions at the same time during episodes of hypoglycemia. Few patients present with severe central system dysfuntion may present with central nervous system dysfunction, such as dizziness, coma, blurred consciousness, anxiety, fear, abnormal behavior and incontinence. Blood glucose fluctuation was the main clinical manifestation of EIAS, which can manifest as recurrent hypoglycemia, and nocturnal hypoglycemia along with daytime hyperglycemia. There were still recurrent episodes of hypoglycemia after stopping exogenous insulin for longer than 5 half-lives. Blood glucose levels generally ranged from 1 to $3 \mathrm{mmol} / \mathrm{L}$ at the time of hypoglycemia. The OGTT is usually used to determine the dynamic changes of glucose, insulin and C-peptide fluctuations in the reaction [9]. The OGTT showed normal fasting blood glucose ( $\sim 5.59 \mathrm{mmol} / \mathrm{L}$ ), insulin and $\mathrm{C}$ peptide aberration. EIAS patients usually have a higher serum insulin concentration, and their C-peptide and proinsulin levels may or may not increase. Many scholars recommend measuring the ratio of insulin to C-peptide to diagnose IAS [2].

IAS is caused by a large amount of IAA against insulin and/or proinsulin in the circulation $[3,10]$. IAA is the first-line test to determine the cause of hypoglycemia in nondiabetic adults in the recently published clinical practice guidelines by the American Endocrine Society [11]. The predominant immunoglobulin of IAA is IgG; other immunoglobulins, such as IgM, IgA and IgE, have also been reported [12]. IAA can be divided into low affinity/high capacity and high affinity/low capacity [13]. The presence of such endogenous binding antibodies distorts glucose metabolism in states of hyper- and hypoglycemia. The severity and duration of hypoglycemia and the swing from a hyperglycemic to a hypoglycemic state are closely related to the binding characteristics of insulin to IAA i.e. intrinsic dissociation rate constant (K-1), titer and intrinsic affinity/capacity [3]. Although the presence of insulinbinding antibodies is a common feature of all IAS, some predominantly bind proinsulin and contribute to raising insulin levels by cross-reacting. However, proinsulin has only a tenth of the bioactivity of insulin, and symptoms in some cases are usually milder [3]. Elevated blood glucose levels and diet can stimulate pancreatic $\beta$-cells to produce insulin, which is bound by IAA, thereby rendering insulin ineffective, forming a "reservoir" and causing postprandial hyperglycemia. Then, insulin/proinsulin dissociates from these endogenous antibodies, giving rise to hypoglycemia [14]. However, EIAS is caused by IAA against exogenous insulin, which can bind endogenous and exogenous insulin and cause poor glycemic control and hypoglycemia by a mechanism similar to IAS. The condition may be related to insulin purity, insulin molecular structure, polymerization status, delivery route of insulin, patient immune status, and genetic susceptibility, among other factors [15-19].

Genetic susceptibility plays an important role in the pathogenesis of IAS, especially HLA-B15, HLA-DR4 and HLA-DR7. Eastern Asian patients with a high prevalence of DRB1*0406 are therefore at higher risk of developing IAS than populations with DRB1*0403 and DRB1*0407, whereas Caucasian IAS patients mainly express HLADRB1*0403 [20, 21].

Although several therapeutic approaches to EIAS have been reported, the optimal treatment is yet to be recommended. Patients with mild EIAS can significantly improve their hypoglycemic symptoms by lifestyle intervention and stopping related insulin. Changing therapeutic modalities can help reduce hypoglycemic episodes (note that bovine/porcine insulin and insulin analogs could trigger EIAS) [22]. Treatment of patients with EIAS includes glucocorticoids, immunoglobulin infusions or immunosuppressive agents such as mycophenolate mofetil, cyclophosphamide and rituximab, and plasmapheresis therapy can be performed if necessary [23-26]. Recently, medical nutrition therapy was effective in the management 
of hypoglycemia induced by EIAS and provided a new idea for the treatment of EIAS [6]. A CGM may be an effective treatment for IAS or EIAS. CGMs have been successfully used in IAS refractory to steroids, and flash glucose monitoring (FGM) has been successfully used in $\alpha$-lipoic acid-induced IAS [27, 28].

EIAS is a self-limiting disease and hypoglycemia can subside and disappear within a few months after discontinuing the related insulin. Patients with EIAS did not have recurrent hypoglycemia during the follow-up period with or without corticosteroids. IAA became negative from 1 to 12 months after the discontinuation of insulin due to the half-life of immunoglobulin antibodies (3-4 weeks). Existing studies have found that IAS and EIAS have no significant differences in the remission rate of hypoglycemia, treatment strategies and prognosis, while persistent hypoglycemia occurs in IAS patients and alternating hypoglycemia and hyperglycemia occurs in most EIAS patients, similar to our research [29]. Defining the difference between IAS and EIAS still requires more research.

\section{Conclusions}

EIAS should be considered in poorly controlled diabetic patients receiving any form of insulin. The single most important diagnostic test is a high concentration of insulin antibodies. Antibody characteristics, which vary from patient to patient, determine the impact on glucose metabolism and dynamics. Changing therapeutic modalities could help reduce hypoglycemic episodes.

\section{Abbreviations}

IAS: Insulin autoimmune syndrome; EIAS: Exogenous insulin autoimmune syndrome; MRI: Magnetic resonance imaging; OGTT: Oral glucose tolerance; GADA: Glutamic Acid Decarboxylase Antibody; CT: Computed tomography; HL: Histocompatibility leukocyte antigen; IGT: Impaired glucose tolerance; IAA: Insulin autoantibody; CGM: Continuous glucose monitor; FGM: Flash glucose monitoring.

\section{Acknowledgements}

None.

\section{Authors' contributions}

Conception and design: CW and ZL. Writing, review, and revision of the manuscript: CW, ZL, WF, LZ, SL and DY. All authors read and approved the final manuscript.

\section{Funding}

This study was supported by research grants from the Key scientific research project of State Administration of Traditional Chinese Medicine of Hunan (201335), National Natural Science Foundation of China (81900344) and Natural Science Foundation of Hunan (2018JJ3795).

\section{Availability of data and materials}

The datasets used and/or analysed during the current study are available from the corresponding author on reasonable request.

\section{Declarations}

Ethics approval and consent to participate

Not applicable.

Consent for publication

Not applicable.

\section{Competing interests}

The authors declare that they have no competing interests.

\section{Author details}

${ }^{1}$ Department of Pharmacy, The Third Xiangya Hospital, Central South University, No. 138 Tongzipo Road, YueLu District, Changsha 410013, Hunan, China. ${ }^{2}$ Drug Clinical Trial Center, Zhuzhou Central Hospital, Zhuzhou, China. ${ }^{3}$ Xiangya School of Pharmaceutical Science, Central South University, Changsha, China.

Received: 19 February 2021 Accepted: 25 March 2021

Published online: 07 April 2021

References

1. Hirata $Y$, Ishizu $H$, Ouchi $N$, et al. Insulin autoimmunity in a case of spontaneous hypoglycemia. J Jpn Diabet Soc. 1970;13:312-20.

2. Censi S, Mian C, Betterle C. Insulin autoimmune syndrome: from diagnosis to clinical management. Ann Transl Med. 2018:6(17):335.

3. Ismail AAA. The insulin autoimmune syndrome (IAS) as a cause of hypoglycaemia: an update on the pathophysiology, biochemical investigations and diagnosis. Clin Chem Lab Med. 2016;54:1715-24.

4. Uchigata $Y$, Hirata $Y$, Iwamoto $Y$. Drug-induced insulin autoimmune syndrome. Diabetes Res Clin Pract. 2009;83(1):e19-20.

5. Hu X, Chen F. Exogenous insulin antibody syndrome (EIAS): a clinical syndrome associated with insulin antibodies induced by exogenous insulin in diabetic patients. Endocr Connect. 2018;7(1):R47-55.

6. Li R, Mao J, Yu K, et al. Medical nutrition therapy is effective in the management of hypoglycemia caused by insulin antibodies: a case report and literature review. J Am Coll Nutr. 2016;35(1):86-90.

7. Uchigata Y, Hirata Y, Omori Y. A novel concept of type VII hypersensitivity introduced by insulin autoimmune syndrome (Hirata's disease). Autoimmunity. 1995;20:207-8.

8. Yazdanpanah S, Rabiee M, Tahriri M, et al. Evaluation of glycated albumin (GA) and $\mathrm{GA} / \mathrm{HbA} 1 \mathrm{c}$ ratio for diagnosis of diabetes and glycemic control: a comprehensive review. Crit Rev Clin Lab Sci. 2017;54(4):219-32.

9. Stumvoll M, Mitrakou A, Pimenta W, et al. Use of the oral glucose tolerance test to assess insulin release and insulin sensitivity. Diabetes Care. 2000;23(3):295-301

10. Cappellani D, Macchia E, Falorni A, Marchetti P. Insulin autoimmune syndrome (Hirata Disease): a comprehensive review fifty years after its first description. Diabetes Metab Syndr Obes. 2020;13:963-78.

11. Cryer PE, Axelrod L, Grossman AB, et al. Evaluation and management of adult hypoglycemic disorders: an Endocrine Society Clinical Practice Guideline. J Clin Endocrinol Metab. 2009:94:709-28.

12. Halsall DJ, Mangi M, Soos M, et al. Hypoglycemia due to an insulin binding antibody in a patient with an IgA-kappa myeloma. J Clin Endocrinol Metab. 2007:92:2013-6.

13. Brooks-Worrell BM, Nielson D, Palmer JP. Insulin autoantibodies and insulin antibodies have similar binding characteristics. Proc Assoc Am Physicians. 1999;111:92-6.

14. Ismail AAA. The double whammy of endogenous insulin antibodies in non-diabetic subjects. Clin Chem Lab Med. 2008;46:153-6.

15. Oak S, Phan TH, Gilliam LK, et al. Animal insulin therapy induces a biased insulin antibody response that persists for years after introduction of human insulin. Acta Diabetol. 2010:47:131-5.

16. Sauerborn M, Brinks V, Jiskoot W, Schellekens H. Immunological mechanism underlying the immune response to recombinant human protein therapeutics. Trends Pharmacol Sci. 2010;31:53-9.

17. Dahl-Jorgensen $K$, Torjesen $P$, Hanssen KF, et al. Increase in insulin antibodies during continuous subcutaneous insulin infusion and 
multiple-injection therapy in contrast to conventional treatment. Diabetes. 1987;36:1-5.

18. Schernthaner $G$, Borkenstein $M$, Fink $M$, et al. Immunogenicity of human insulin (Novo) or pork monocomponent insulin in HLA-DR-typed insulindependent diabetic individuals. Diabetes Care. 1983;6(Suppl 1):43-8.

19. He H, Yang X, Lv X, et al. The difference of blood glucose fluctuation in type 2 diabetes mellitus patients with positive and negative insulin autoantibodies. Chin J Multiple Organ Dis Elderly. 2012;11:645-9.

20. Uchigata Y, Omori Y, Nieda M, et al. HLA-DR4 genotype and insulinprocessing in insulin autoimmune syndrome. Lancet (London, England). 1992;340(8833):1467.

21. Uchigata Y, Tokunaga K, Nepom G, et al. Differential immunogenetic determinants of polyclonal insulin autoimmune syndrome (Hirata's disease) and monoclonal insulin autoimmune syndrome. Diabetes. 1995;44(10):1227-32.

22. Ismail AAA. Insulin analogues as a new example of interference in insulin assays. Ann Clin Biochem. 2016;53(Pt 1):181-2.

23. Ishizuka T, Ogawa S, Mori T, et al. Characteristics of the antibodies of two patients who developed daytime hyperglycemia and morning hypoglycemia because of insulin antibodies. Diabetes Res Clin Pract. 2009;84:e21-3.

24. Greenfield JR, Tuthill A, Soos MA, et al. Severe insulin resistance due to anti-insulin antibodies: response to plasma exchange and immunosuppressive therapy. Diabet Med. 2009;26:79-82.
25. Jassam N, Amin N, Holland P, et al. Analytical and clinical challenges in a patient with concurrent type 1 diabetes, subcutaneous insulin resistance and insulin autoimmune syndrome. Endocrinol Diabetes Metab Case Rep. 2014;2014:130086.

26. Koyama R, Nakanishi K, Kato M, et al. Hypoglycemia and hyperglycemia due to insulin antibodies against therapeutic human insulin: treatment with double filtration plasmapheresis and prednisolone. Am J Med Sci. 2005;329:259-64

27. Saxon DR, McDermott MT, Michels AW. Novel management of insulin autoimmune syndrome with rituximab and continuous glucose monitoring. J Clin Endocrinol Metab. 2016;101(5):1931-4.

28. Cappellani D, Sardella C, Campopiano MC, et al. Spontaneously remitting insulin autoimmune syndrome in a patient taking alpha-lipoic acid. Endocrinol Diabetes Metab Case Rep. 2018;2018:18-0122.

29. Jinyang Z, Fangfang Y, Sui Y, et al. Comparison of clinical characteristics between insulin autoimmune syndrome and exogenous insulin antibody syndrome. Chin J Diabetes Mellitus. 2020;12(10):830-4.

\section{Publisher's Note}

Springer Nature remains neutral with regard to jurisdictional claims in published maps and institutional affiliations.
Ready to submit your research? Choose BMC and benefit from:

- fast, convenient online submission

- thorough peer review by experienced researchers in your field

- rapid publication on acceptance

- support for research data, including large and complex data types

- gold Open Access which fosters wider collaboration and increased citations

- maximum visibility for your research: over $100 \mathrm{M}$ website views per year

At BMC, research is always in progress.

Learn more biomedcentral.com/submissions 